\title{
Youth Encounters with Internet Pornography: A Survey of Youth, Caregiver, and Educator Perspectives
}

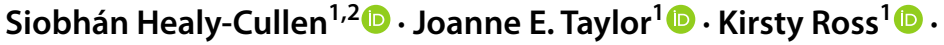 \\ Tracy Morison ${ }^{1,3}$ (D)
}

Accepted: 6 August 2021 / Published online: 14 August 2021

(c) The Author(s) 2021

\begin{abstract}
Despite international inquiry regarding young people's encounters with Internet pornography (IP), there is a lack of knowledge about how their caregivers (parents or guardians) and educators perceive these encounters in comparison to young people. Such knowledge is critical to understanding the synergies and discrepancies that might exist between these key stakeholder groups (youth, caregivers and educators) and across genders, to subsequently inform how to best support youth in navigating IP. To this end, the present study describes youth (16-18-year olds) encounters with IP, as well as caregiver and educator perceptions of these encounters. An online survey was completed by 256 youth and 217 caregivers and educators recruited from nine schools with an existing investment in sexuality education in Aotearoa, New Zealand. Similar to global trends, this group of young New Zealanders were familiar with IP and patterns of encounters were gendered. However, there were varied understandings between stakeholder groups and across genders as to why and how these encounters occur. Understanding the ways youth encounter IP_-and exploring how caregivers and educators perceive these encounters-serves as a springboard for future research that considers the broader socio-cultural context within which these perspectives are constructed.
\end{abstract}

Keywords Internet pornography · New Zealand · Youth · Caregivers · Educators

Siobhán Healy-Cullen

siobhanhcullen@gmail.com

1 School of Psychology, Massey University, Private Bag 11 222, Palmerston North 4442, New Zealand

2 School of Psychology, National University of Ireland, Galway, Ireland

3 Critical Studies in Sexualities and Reproduction, Rhodes University, Makhanda, South Africa 


\section{Introduction}

Youth encounters with Internet pornography (IP) have led to global concern regarding the healthy sexual socialisation of youth (Scarcelli, 2014; Tomić et al., 2017). The majority of research in this field is framed using a harms-based lens, often with a view to ameliorating negative effects and regulating youth encounters with IP (Bragg \& Buckingham, 2009). Such research provides a broad understanding of young people's encounters with IP, but does not explore the relevance of IP in the lives of young people, or their thoughts about the involvement of caregivers and educators in youth IP viewing (Attwood et al., 2018). This is problematic because research on sexuality education suggests that there is frequently a disconnect between the ways youth understand and engage with sexual matters and the ways adults tasked with their sexual socialisation believe that they do (Jackson, 2004; Jearey-Graham \& Macleod, 2015). Failing to bridge this divide undermines attempts at providing sexuality education that is relevant to youth, including assisting young people to navigate the realities of a digital world that affords increasingly easy, anonymous, and free access to diverse online sexual content (Davis et al., 2019). Thus, in addition to a broader understanding of young people's encounters with IP, it is also important to understand how caregivers and educators perceive young people's encounters with IP, given their roles in sexuality education.

Although there is a large body of research on youth engagement with various mediated intimacies (e.g., sexting) (Stanley et al., 2018; Widman et al., 2021), no published work to date has concurrently examined the perspectives of caregivers and educators as well as young people about youth encounters with IP. Additionally, given IP is an inevitably gendered topic (Attwood, 2005), it is unknown as to whether, like youth encounters, these adult perceptions are gendered. Such knowledge is critical to further understand how adults might support young people in negotiating the IP they encounter (Sorbring et al., 2015). The present study aims to address this knowledge gap.

\section{Young People and Internet Pornography}

The prevalence of young people's encounters and engagement with IP is difficult to ascertain as it depends on cultural context and research design (Lim et al., 2017; Ybarra \& Mitchell, 2005). In Aotearoa New Zealand, where the current research was conducted, a recent nationally representative government survey suggests that $67 \%$ of $14-17$-year olds have seen IP (Office of Film \& Literature Classification, 2018). International research suggests that encounters with IP are more prevalent among boys than girls, and boys are more likely to report intentionally seeking out IP, more regularly, and from a younger age (Ševčíková \& Daneback, 2014; Stanley et al., 2018). Qualitative research suggests that these patterns are tied to binary gender norms that demarcate pornography viewing as a male activity (Albury, 2018; Spišák, 2017). Indeed, much of the literature on 
youth encounters with IP takes a binary view of gender, although IP viewing may be more frequent among LGBTQ youth (Bőthe et al., 2019).

International research also indicates that IP is a key medium young people turn to when seeking information about sex and relationships (Brown \& L'Engle, 2009; Štulhofer et al., 2010). In New Zealand, $71 \%$ of youth surveyed reported using IP as a tool for learning about sex and sexuality, including for their own sexual practices (Office of Film \& Literature Classification, 2018), so IP also functions as a cultural resource and source of education about sex (Löfgren-Mårtenson \& Månsson, 2010). IP may act as a source of sexual socialisation in the absence of input from significant adults, given that youth report a lack of communication about IP with their caregivers, difficulty in talking to them about the topic, and a general lack of information about IP in sexuality education (Pound et al., 2016; Priebe et al., 2013).

Minimal research contributes to an understanding of how caregivers can play a role in young people's encounters with IP as a cultural resource (Scarcelli, 2014), especially how caregivers perceive and understand youth encounters more generally, and what this means for their communication with youth about IP (Livingstone \& Bober, 2004; Rothman et al., 2017). Caregivers perceive youth encounters with IP as inherently negative, and are fearful and embarrassed about discussing the issue with youth, even if they would like open dialogue on the topic (Davis et al., 2019; Dawson, 2020; Tsaliki, 2011; Widman et al., 2021; Zurcher, 2017). Gender influences how parents communicate with youth about IP, with fathers reportedly less likely to engage in discussion than mothers (Boniel-Nissim et al., 2020). Double standards also exist in gender socialisation, as parents may also be more likely to condone IP viewing among young men than women, attributing male interest to 'natural' sexual urges (Gesser-Edelsburg \& Arabia, 2018; Tolman, 2013).

Educators are another important group of adults in the lives of youth, with schools acting more broadly as key domains of sexual socialisation. Some schools and individual educators may be reluctant to provide instruction on sexually contentious topics (e.g., abortion, masturbation, and IP) which, in some instances, may be borne out of apprehension of caregiver responses, or the values and ethos of the school (Shtarkshall et al., 2007; Weaver et al., 2001). Whether and how schools approach the issue of IP in sexuality education will shape the sexual socialisation of students in various ways, yet little is known about how educators perceive young people's encounters with IP.

One survey of educators in the UK reported that teachers perceived viewing IP to have negative effects on youth and that schools should teach about these potential risks (Baker, 2016). Similarly, participants in a Swedish focus group study that included a small number of teachers discussed the ways IP conveys contradictory messages to youth in comparison to other domains of socialisation, and therefore educators should be equipped with the skills to discuss this topic with youth (Mattebo et al., 2014). Research primarily from the UK and Australia posits that broaching the subject of IP in the classroom is an uncomfortable and "high risk proposition" that requires training, resources, and the support of the school community (Albury, 2014, p. 173, 2018; Baker, 2016; Ollis, 2016).

Given the limited research on caregiver and educator perceptions about young people's encounters with IP, and the lack of consideration of their views 
alongside those of youth themselves, the present study describes young people's (aged 16-18-year-old) encounters with IP and their caregivers' and educators' perceptions of these encounters. A descriptive rather than inferential approach was taken given that IP is under-researched in New Zealand and it is as yet unknown whether there are sociocultural factors that might impact such research, such as the perspectives of Māori (the indigenous people of New Zealand) young people and adults regarding IP, and the diversity of school-based sexuality education. Our research was also part of a larger mixed methods study that was situated within critical social psychology and based on a social constructionist approach. Therefore, our focus was to describe the characteristics of youth encounters with IP from the perspectives of youth, caregivers, and educators and to identify similarities and divergences for interpretation through a sociocultural lens.

\section{Method}

Data were collected through a cross-sectional online survey as part of a broader mixed methods study about youth encounters with IP in New Zealand (Healy-Cullen et al., 2021a, b). The survey elicited the perspectives of students aged 16-18 years, caregivers (parents and guardians), and educators on this topic.

\section{Participants}

Participants were recruited from nine high schools with various characteristics (e.g., co-educational, single sex, rural, urban, and differing decile ${ }^{1}$ groupings). While 249 schools were invited to take part, many declined, noting they were not able to bring the topic into their school for a range of reasons, despite the importance of the topic. This meant that the participating schools tended to be more interested in the topic in general, and do not represent a full range of perspectives. Each school decided on the process of providing information about the study and survey dissemination to young people and their caregivers and educators, and we therefore could not ascertain response rates given the varying approaches used. However, a total of 473 responses were collected, $256(54.12 \%)$ from youth and $217(45.88 \%)$ from adults, 98 of whom were caregivers (45.16\%), 73 educators (33.64\%), and 46 people were both caregivers and educators $(21.20 \%)$. The average age of students was 16.69 years $(S D=0.68)$. Most participants identified as New Zealand European/ Pākehā (i.e., New Zealander of European descent). Table 1 provides demographic details for the participants.

\footnotetext{
${ }^{1}$ In New Zealand, school deciles indicate the extent a school draws students from low socio-economic communities. Decile 1 schools have the highest proportion of students from low socio-economic communities, whereas decile 10 schools have the lowest. No schools from deciles $0-2$ accepted the invitation to participate.
} 
Table 1 Participant demographic characteristics (\%)

\begin{tabular}{|c|c|c|c|c|c|}
\hline & $\begin{array}{l}\text { Youth } \\
(N=256)\end{array}$ & $\begin{array}{l}\text { All adults } \\
(N=217)\end{array}$ & $\begin{array}{l}\text { Caregivers } \\
(n=98)\end{array}$ & $\begin{array}{l}\text { Educators } \\
(n=73)\end{array}$ & $\begin{array}{l}\text { Caregivers } \\
\text { and educators } \\
(n=46)\end{array}$ \\
\hline \multicolumn{6}{|l|}{ Gender } \\
\hline Male & 51.95 & 43.32 & 30.61 & 53.42 & 54.35 \\
\hline Female & 39.45 & 45.62 & 62.24 & 35.62 & 26.09 \\
\hline Gender diverse & 8.60 & 11.06 & 7.14 & 10.96 & 19.57 \\
\hline \multicolumn{6}{|l|}{ Age } \\
\hline 16 years & 43.48 & & & & \\
\hline 17 years & 43.87 & & & & \\
\hline 18 years & 12.65 & & & & \\
\hline $16-25$ years & & 27.78 & 22.68 & 43.84 & 13.04 \\
\hline $26-35$ years & & 10.19 & 6.19 & 16.44 & 8.70 \\
\hline $36-45$ years & & 18.98 & 21.65 & 12.33 & 23.91 \\
\hline $45-55$ years & & 24.07 & 35.05 & 9.59 & 23.91 \\
\hline Older than 55 years & & 18.98 & 14.43 & 17.81 & 30.43 \\
\hline \multicolumn{6}{|l|}{ Ethnicity } \\
\hline New Zealand European/Pākehā & 64.50 & 73.30 & 76.50 & 72.60 & 67.40 \\
\hline New Zealand Māori & 27.70 & 14.30 & 15.30 & 15.10 & 10.90 \\
\hline Asian & 12.10 & 17.00 & 1.00 & 5.50 & 13.00 \\
\hline Other ethnicity & 11.70 & 5.10 & 14.30 & 16.40 & 23.90 \\
\hline
\end{tabular}

Pākehā is the indigenous term for non-Māori/non-Polynesian New Zealanders

\section{Procedures}

School principals distributed electronic information sheets about the study for students aged 16-18-year, caregivers, and educators, along with an invitation to take part in the online survey. Principals communicated this information in ways suitable to their specific school community (e.g., mailing lists) in accordance with ethical protocol regarding consent. The working definition of IP provided the beginning of the survey was "any sexually explicit [Internet] material displaying genitalia with the aim of sexual arousal or fantasy” (Short et al., 2012, p.21). There were 27 questions for youth and 13 questions for adults about youth encounters with IP, made up of a combination of ranking order (respondents ranked their answers in order of applicability, and selected the options that were relevant to them), Likert scale questions (i.e., $1=$ strongly disagree to $5=$ strongly agree), closed questions (which always had an 'other' option and space for further comment), and open-ended questions. The youth survey included questions about demographic details, age of first encounter, access to IP, intentionality and frequency of viewing, primary reasons for accessing IP, where, how and with whom IP is accessed, perceived personal effects of IP viewing in comparison to peers, sources of sexuality education, and experiences of education/communication about IP at home or school. A key open-ended question in the youth survey was; "Have you received any education about Internet 
pornography? If yes, where did you receive this education from?". These questions were informed and developed from international literature that has investigated young people's encounters with IP (e.g., Mattebo et al., 2014; Ybarra \& Mitchell, 2005), rather than using 'scientific' measures more familiar to clinical, positivist research designs where hypotheses and generalisation are appropriate (Fisher \& Kohut, 2020).

To compare with youth, caregivers and educators were asked the same questions as youth, outlined above, regarding their perceptions of young people's encounters with IP. The same open-ended question to educators and caregivers was phrased accordingly; "Have you delivered any education about IP to the young person in your care? If yes, please outline what you discussed". Due to a problem with the survey setup that was not detected until data collection was completed, data were missing for two questions related to the educator group, namely, their perceptions of youths' primary reasons for viewing IP and sources of information about sex and sexuality.

\section{Data Analysis}

Data were used descriptively rather than inferentially as we did not aim to make inferences beyond the sample. Thus, power analysis and tests of statistical significance were not relevant. Descriptive data (such as measures of central tendency and frequency distributions) were used to explore variability in the data between the groups and by gender. The data distributions were checked (overall, for each group, for gender, and for gender within each group) and there was no skewness or bimodal distributions, so the mean was used as the measure of central tendency. Ranked data were collated across the sample as a frequency count, and rankings were determined using a weighted sum calculation (i.e., the weighted sum for the response that was ranked first was worth more than the response ranked last). Thematic analysis was completed for the open-ended questions described above using Nvivo 12 to assist coding (Braun \& Clarke, 2012).

\section{Results}

\section{Youth Encounters with Internet Pornography}

Most young people $(85.31 \%)$ had seen IP on one or more occasion, either intentionally or unintentionally, at some point in their life. This was the case for $95.20 \%$ of boys, $70.41 \%$ of girls, and $95.45 \%$ of gender diverse youth. Of those who had seen IP, the average age of first encounter was 11.70 years $(S D=3.32)$, although this differed according to gender; the average age for boys was similar to the overall average at 11.33 years $(S D=3.16)$, older for girls at 12.83 years $(S D=2.12)$, and younger for gender diverse youth at 10.10 years $(S D=5.56)$. Across groups, adults perceived youth encounters to occur earlier than youth themselves reported, on 
average at 10.58 years $(S D=3.40)$, with similar reports within each group of adults (caregivers: $M=11.20$, educators: $M=10.08$, caregivers and educators: $M=10.18$ ).

For just over half of youth $(54.68 \%)$, their first encounter with IP was unintentional. However, this varied based on gender, with more boys (59.29\%) and gender diverse youth (42.86\%) reporting an intentional first encounter than girls $(23.19 \%)$. For those whose first encounter was unintentional, the most frequent reasons were being shown by peers, happening across it while browsing, and pop-up advertisements. Some of the other reasons provided by female youth as open comments included "I opened a relative's iPad and it was accidentally left on it", "Brother didn't exit the tab", and "Watching anime".

Of those youth who unintentionally came across IP for the first time, most (76.15\%) did not tell anyone about it. Additionally, from that group, more boys $(86.96 \%)$ than girls $(69.23 \%)$ and gender diverse youth $(63.64 \%)$ did not disclose to someone. Of those who did tell someone, this person was most frequently a peer for boys $(83.33 \%)$ and girls $(56.25 \%)$. Gender diverse youth more frequently told a teacher $(50.00 \%)$, although neither boys nor girls told a teacher. However, $16.67 \%$ of boys and $37.50 \%$ of girls told a caregiver, while no gender diverse youth told their caregiver.

Similar to the gendered patterns among youth, more male adults across groups indicated that youth would not tell a caregiver or educator compared to female and gender diverse adults across groups (see Table 2). Additionally, across genders, those in the educator group reported that youth would not disclose unintentional encounters to IP to them (see Table 2; note that caregivers were not asked about disclosure to educators, and educators were not asked about disclosure to caregivers). In terms of the content they had seen, just over half of youth $(52.49 \%)$ indicated that they would describe what they had seen as 'hardcore', based on their own definition (see Table 3).

\section{Frequency of Internet Pornography Viewing}

There were gendered patterns in young people's viewing of IP. Girls most frequently had seen IP once $(38.46 \%)$ or once or twice a year $(20.00 \%)$, while nearly a quarter of boys viewed IP 2-4 times a week (24.51\%) and $45.00 \%$ of gender diverse youth viewed IP more than once a day. Additionally, whenever they viewed IP, boys and gender diverse youth more frequently viewed for longer periods of time than girls (see Table 3). When asked to compare the frequency that they viewed IP with that of their peers, youth were generally uncertain as to how much IP they viewed compared to their peers, or thought they viewed the same. However, as shown in Table 3, 45.90\% of girls perceived their viewing to be "much less" than their counterparts, while $31.60 \%$ of gender diverse youth reported viewing "much more".

\section{Access to Internet Pornography}

Young people reported that they generally viewed IP on mobile phones $(65.71 \%)$ rather than desktop computers or tablets, with the majority watching IP alone 


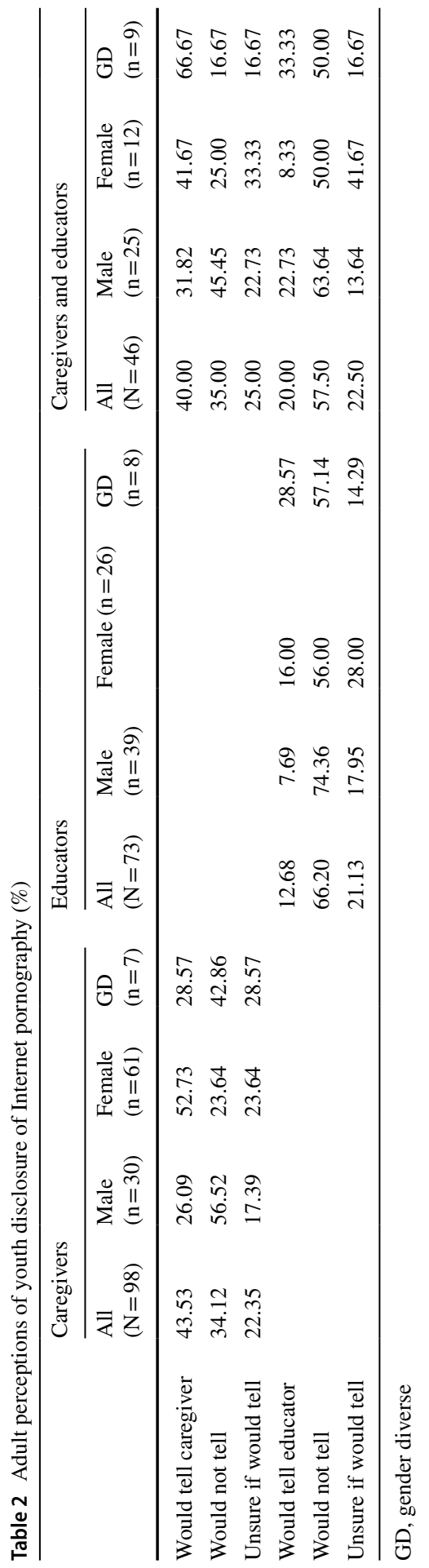


Table 3 Youth responses about Internet pornography (\%)

\begin{tabular}{|c|c|c|c|c|}
\hline Survey item & $\begin{array}{l}\text { All youth } \\
(\mathrm{n}=256)\end{array}$ & $\begin{array}{l}\text { Girls } \\
(\mathrm{n}=101)\end{array}$ & $\begin{array}{l}\text { Boys } \\
(\mathrm{n}=133)\end{array}$ & $\begin{array}{l}\text { Gender diverse } \\
(\mathrm{n}=22)\end{array}$ \\
\hline \multicolumn{5}{|l|}{ Frequency of IP viewing } \\
\hline Only once & 18.18 & 38.46 & 6.86 & 10.00 \\
\hline Once or twice a year & 9.63 & 20.00 & 4.90 & 0.00 \\
\hline Every couple of months & 10.16 & 12.31 & 9.80 & 5.00 \\
\hline Every month & 10.16 & 10.77 & 10.78 & 5.00 \\
\hline Once a week & 11.23 & 6.15 & 15.69 & 5.00 \\
\hline 2-4 times a week & 17.65 & 7.69 & 24.51 & 15.00 \\
\hline Once a day & 9.63 & 1.54 & 13.73 & 15.00 \\
\hline More than once a day & 13.37 & 3.08 & 13.73 & 45.00 \\
\hline \multicolumn{5}{|l|}{ Time spent viewing IP } \\
\hline Less than $10 \mathrm{~min}$ & 49.15 & 41.18 & 73.21 & 21.05 \\
\hline Less than $30 \mathrm{~min}$ & 30.51 & 35.29 & 21.43 & 31.58 \\
\hline Between $30 \mathrm{~min}$ and an hour & 5.65 & 7.84 & 3.57 & 0.00 \\
\hline More than an hour & 1.13 & 1.96 & 0.00 & 0.00 \\
\hline More than $2 \mathrm{~h}$ & 13.56 & 13.73 & 1.79 & 47.37 \\
\hline \multicolumn{5}{|l|}{ IP viewing compared to peers } \\
\hline Much less & 26.00 & 45.90 & 14.40 & 21.10 \\
\hline Less & 12.40 & 6.60 & 17.50 & 5.30 \\
\hline The same & 27.10 & 11.50 & 37.10 & 26.30 \\
\hline More & 3.40 & 4.90 & 3.10 & 0.00 \\
\hline Much more & 10.70 & 3.30 & 11.30 & 31.60 \\
\hline Unsure & 20.30 & 27.90 & 16.50 & 15.80 \\
\hline \multicolumn{5}{|l|}{ Seen 'hardcore' IP } \\
\hline Yes & 52.49 & 37.50 & 58.59 & 72.22 \\
\hline No & 24.86 & 23.44 & 26.26 & 22.22 \\
\hline Unsure & 22.65 & 39.06 & 15.15 & 5.56 \\
\hline \multicolumn{5}{|c|}{ IP practices applied in personal life } \\
\hline Yes & 39.89 & 46.46 & 26.15 & 52.63 \\
\hline No & 43.17 & 39.39 & 55.38 & 21.05 \\
\hline No, but I would like to & 7.65 & 7.07 & 7.69 & 10.53 \\
\hline No, I would not like to & 6.56 & 6.06 & 9.23 & 0.00 \\
\hline Other & 2.73 & 1.01 & 1.54 & 15.79 \\
\hline \multicolumn{5}{|c|}{ Perceptions of caregiver awareness } \\
\hline Caregivers are aware & 27.93 & 29.59 & 14.29 & 66.67 \\
\hline Caregivers are not aware & 27.93 & 22.45 & 42.86 & 5.56 \\
\hline Unsure of caregiver awareness & 44.13 & 47.96 & 42.86 & 27.78 \\
\hline \multicolumn{5}{|l|}{ Education received about IP } \\
\hline Received any education & 37.38 & 51.52 & 16.84 & 65.00 \\
\hline Did not receive any education & 62.62 & 48.48 & 83.16 & 35.00 \\
\hline Sources of this education & $n=80$ & $n=16$ & $n=51$ & $n=13$ \\
\hline Teacher in sexuality education & 61.25 & 68.75 & 64.71 & 38.46 \\
\hline External educator in school & 12.50 & 12.50 & 11.76 & 15.38 \\
\hline
\end{tabular}


Table 3 (continued)

\begin{tabular}{lllll}
\hline Survey item & $\begin{array}{l}\text { All youth } \\
(\mathrm{n}=256)\end{array}$ & $\begin{array}{l}\text { Girls } \\
(\mathrm{n}=101)\end{array}$ & $\begin{array}{l}\text { Boys } \\
(\mathrm{n}=133)\end{array}$ & $\begin{array}{l}\text { Gender diverse } \\
(\mathrm{n}=22)\end{array}$ \\
\hline Caregivers & 8.75 & 18.75 & 5.88 & 7.69 \\
Peers & 3.75 & 0.00 & 3.92 & 7.69 \\
The Internet & 2.50 & 0.00 & 3.92 & 0.00 \\
Other & 11.25 & 0.00 & 9.80 & 30.77 \\
\hline
\end{tabular}

(75.00\%) rather than with peers or partners. Most youth indicated that they "could definitely" $(51.40 \%)$ or "probably" $(25.70 \%)$ access IP at home without their caregiver knowing, if they wanted to. At school, almost a fifth $(19.25 \%)$ of youth responded that they "definitely could not" access IP, while a third (33.33\%) indicated that they definitely could.

Aligning with youth responses, caregivers reported that youth could "definitely" or "probably" access IP at home $(45.88 \%, 35.29 \%$ respectively), while educators reported that youth could "definitely" or "probably" access IP at school $(30.56 \%$, $37.50 \%$ respectively) without their knowledge. However, male teachers more frequently indicated that students could "definitely not" access IP at school (17.95\%) compared to female $(3.85 \%)$ and gender diverse educators $(0.00 \%)$.

\section{Primary Reasons for Viewing Internet Pornography}

Participants were asked to rank a list of possible motivations that young people might have for viewing IP. Overall, across stakeholder groups, curiosity was ranked as the primary motivation (see Fig. 1a). However, thereafter there was some divergence between the rankings of adults (caregivers and educators) and youth, indicating a discrepancy in understandings between these groups. Young people included "boredom" and "to wind down and relax" among their top five reasons for IP viewing, but adults did not include these reasons. Rather, they ranked peer influence and learning about sex more highly (see Fig. 1b).

There were gendered differences among youth in terms of their primary reasons for seeking out IP (see Fig. 1b). Sexual gratification was given as a primary motivation by male youth, who, for example gave reasons such as "cause I'm horny" (male student), and "pleasure" (male student). Only girls indicated in their top five reasons that IP was used as a way to learn about sex, sexual acts, and sexuality. For example, in the open-ended comments relating to this question, they said: "To understand how sexual encounters happen as school does not teach this and $\mathrm{i}$ [sic] want to be able to feel okay for my first time, by know [sic] the 'lingo' and knowing what to do" (female student). Compared to girls (26.15\%), more boys (46.46\%) and gender diverse youth $(52.63 \%)$ had engaged in sexual practices that they had also seen in IP (see Table 3).

Adult perceptions of the reasons that youth seek out IP also varied according to their own gender. Like female youth, sexual gratification was ranked less frequently by women than men and gender diverse adults across stakeholder groups 


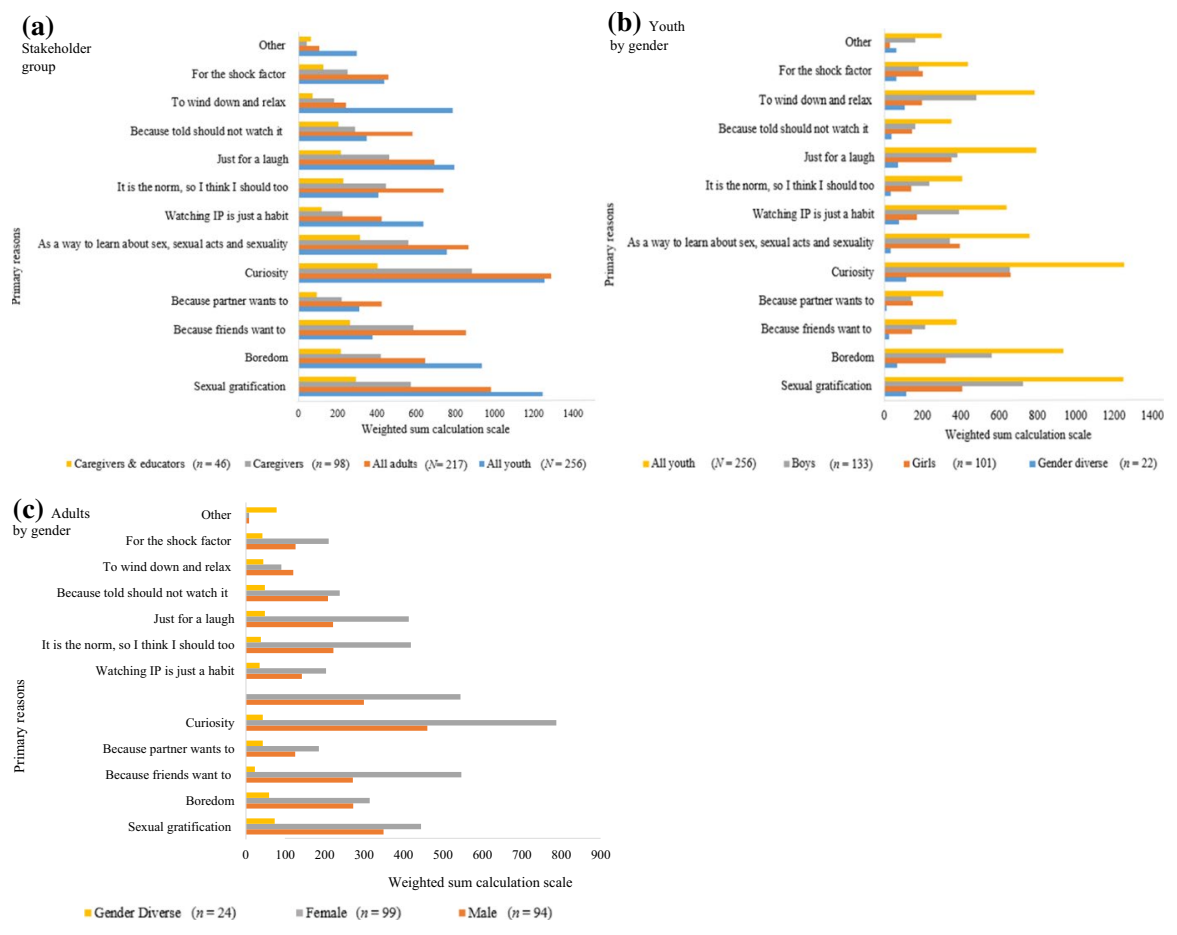

Fig. 1 Primary reasons youth seek out Internet pornography by stakeholder group (a), youth by gender (b), and adults by gender (c)

(see Fig. 1c). Also mapping onto trends in youth responses, "boredom" was ranked in the top five perceived reasons by men and gender diverse adults across stakeholder groups, whereas this was not the case for women. Additionally, "because their friends want to" was ranked particularly highly by female caregivers as their second perceived reason for youth viewing.

\section{Primary Sources of Information About Sex and Sexuality}

Participants were asked to rank young people's primary sources of information about sex and sexuality. Across the stakeholder groups, there was a shared understanding that peers are a primary source of information about sex and sexuality for youth (see Fig. 2a). When it came to young people themselves, IP was ranked third by boys and gender diverse youth, and sixth by girls. Adults ranked caregivers as an information source third overall; however, this did not feature as high from the perspective of gender diverse youth, who ranked caregivers last (see Fig. 2b).

There were some differences between adults' responses depending on stakeholder group. Overall, the rankings of participants who were educators as well as caregivers more closely aligned with youth rankings than those who were only caregivers. In particular, these respondents gave a higher ranking to the Internet and IP as 

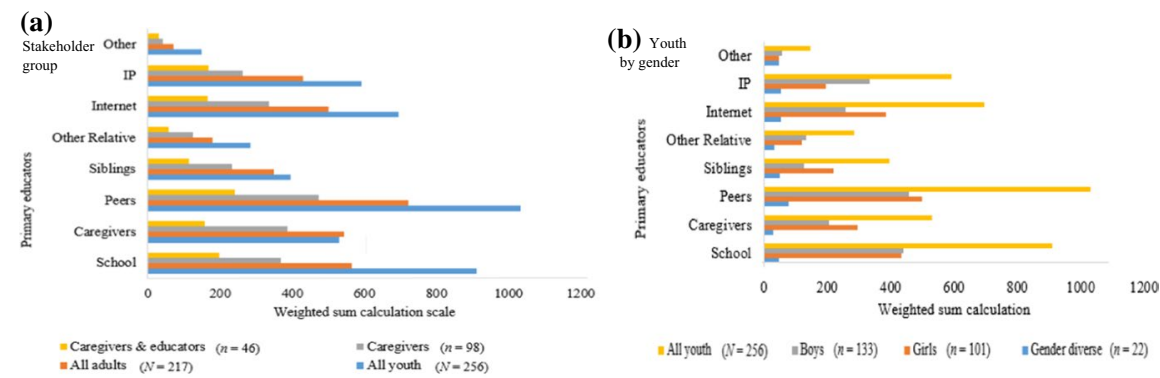

(c) Caregivers

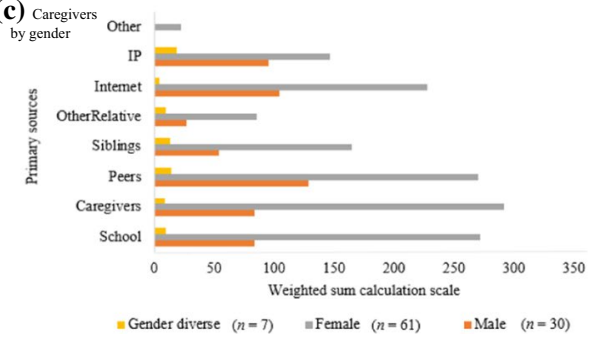

Fig. 2 Primary educators for youth about sex and sexuality by stakeholder group (a), youth by gender (b), and caregivers by gender (c)

a source of information than caregivers, who ranked themselves more highly than either the Internet or IP (see Fig. 2a).

Differences among adult participants also related to gender, mapping on to the gender patterns observed among youth. Most notably, female caregivers were the only cohort who most frequently ranked themselves as young people's primary information source (i.e., first). Male and gender diverse caregivers perceived IP as a more important information source about sex and sexuality than caregivers (see Fig. 2c).

\section{Communication with Youth About Internet Pornography}

Many $(44.13 \%)$ of the youth were unsure if their caregivers knew whether they had seen IP. Girls reported less frequently $(14.29 \%)$ than boys $(29.59 \%)$ or gender diverse youth $(66.67 \%)$ that their caregivers were aware of their IP viewing (see Table 3).

Many caregivers were aware that youth in their care had seen IP (48.39\%), approximately a third were also unsure (34.68\%), while a small proportion (16.94\%) did not think that the young person in their care had ever seen IP. Overall, more than half $(56.91 \%)$ of caregivers had provided some education about IP to the young person in their care, but only a small number $(8.75 \%)$ of youth reported that any education they had received was from caregivers (see Table 3). Girls also reported less frequently that they had received any education about IP in comparison to boys and gender diverse youth (see Table 3). Additionally, female caregivers more frequently 
reported that they delivered education about IP to youth (72.73\%) compared to male $(38.64 \%)$ or gender diverse $(38.46 \%)$ caregivers.

Of the $30.36 \%$ of educators who indicated that there had been some delivery of education about IP at their school $(40.18 \%$ were unsure, while $29.46 \%$ indicated that there had not been any), this education was most often provided by a teacher during sexuality education at the school $(63.64 \%)$, rather than (for example) external providers $(27.27 \%)$. This maps on to the youth findings, as of the $37.38 \%$ of youth who indicated they had received any education about IP, most (61.25\%) reported that this was predominantly delivered by a teacher as part of sexuality education in school (see Table 3).

\section{Messages Delivered About Internet Pornography to Youth by Caregivers}

Caregivers were asked to describe what they had discussed about IP at home with the young person in their care. There were a broad range of responses to this openended question that were thematically organised.

\section{Internet Pornography is Harmful}

Overall, IP was portrayed in a negative light and discussed with youth in relation to the "ugliness that can pop up in the world", "offensive sites", the "dark web", "pedophiles [sic]", "incredibly evil people", and subject to monitoring by "the Internet police". Most caregivers indicated that IP was harmful, addictive, unsuitable, and dangerous, for instance, something "that is not acceptable in our household". This was primarily related to the potential deleterious impacts or "nasty consequences" of IP viewing, which ranged from being "psychologically unhealthy" to "potentially harmful for future relationships and self". For some, this harm was conceptualised as "temptation to sin" and "alienation from God". IP was also described as objectifying, degrading, abusive, and exploitative of women.

\section{Avoid Viewing Internet Pornography}

While some caregivers acknowledged that curiosity was to be expected among youth, and they should not feel badly about experiencing arousal if they happen across IP, youth were still encouraged to avoid it. While not necessarily forbidden, many caregivers voiced their disapproval of IP viewing to youth, while others censored it; for example, "please don't watch it", "we operate open DNS for their protection".

\section{Internet Pornography is not 'Real'}

Another primary message that caregivers reported delivering to youth about IP was that it is fake and unrealistic; a performance by paid actors/actresses. This idea of "reality vs. fantasy" was a distinction taken up by many caregivers, highlighting that IP is not "a reflection of true intimacy between people", and "not a true depiction 
of real sex". How IP might be compared to 'real life' was often mentioned in the context of intimacy and consent "which is not indicative of normal healthy sexual relationships".

\section{‘Think...'}

Responses indicated that caregivers delivered education to youth about IP based on their own views; "I believe [emphasis added] Internet pornography degrades and objectifies women", or "I'm [emphasis added] not a fan of pornography". Thus, it may understandably be the case that youth are receiving a variety of messages about IP that are based on particular perspectives, beliefs, and worldviews, such as religious affiliations (e.g., "We have a pornography education resource which is offered by the Church of Jesus Christ of Latterday Saints").

\section{Discussion}

This study provides some insights into encounters with IP among these New Zealand youth, including their initial encounters, viewing regularity, and motivations for viewing IP. Additionally, this study provides an understanding of the perceptions of these caregivers and educators, as key domains of sexual socialisation. In the following discussion, we contextualise our findings in relation to the wider context in which youth IP viewing is deemed largely negative and shameful, particularly for girls (Ashton et al., 2018; Ševčíková \& Daneback, 2014). The findings are also contextualised within the limitations of who these participants were (i.e., members of school communities who were already invested in sexuality education), and we recognise that a full range of perspectives are not represented.

\section{Youth Encounters with Internet Pornography}

Our findings are consistent with international research, showing that most young people $(85.31 \%)$ have seen IP on one or more occasion at some point in their life, either intentionally or unintentionally (Martellozzo et al., 2017; Peter \& Valkenburg, 2016). Additionally, for many young people, particularly girls, first encounters were reported as unintentional $(54.68 \%)$, often as a result of being shown by peers or pop-up links appearing while browsing the Internet. Consistent with previous findings, of those young people in the study who unintentionally came across IP, most (76.15\%) did not tell anyone about their encounter (Braun-Courville \& Rojas, 2009; Lim et al., 2017).

Of youth who had seen IP before, the average age of first encounter was approximately 12 years old, which was slightly older than what adults perceived (10.58 years). Adults' assumption of a younger age may reflect the public concern-often amplified by the media - about IP viewing among young people (Taylor, 2020). Although there is variation regarding first encounters in the literature, that these young New Zealanders first encountered IP at approximately 12 years old 
is slightly younger than global trends and a previous New Zealand report (Office of Film \& Literature Classification, 2018). However, encountering IP during early teenage years is unsurprising given sexual curiosity (Ybarra \& Mitchell, 2005), and perhaps coincides with personal internet access via mobile phone.

Gender diverse youth reported viewing IP at a younger age (10.10 years) than their female and male peers, and may be exploring their identity and sexuality in a world where there are not as many resources to do this with, or people to talk with (Collier et al., 2013). Our research suggests that some young people seek out IP to try to learn about sex, and this occurs alongside reluctance to discuss sex (and particularly IP) with adults, and their perception of adults being reluctant to discuss it with them, consistent with previous findings about IP as a source of information about sex and sexuality (Martellozzo et al., 2017; Rothman et al., 2018).

\section{Sexuality Education and Internet Pornography}

Many youth stated that they did not receive any education about IP as part of their sexuality education (62.62\%), despite most having seen IP, consistent with the wider literature that suggests IP is often omitted from conversation among youth and adults, perhaps on account of the perceived difficulties in having such conversations (Albury, 2018). In New Zealand, and internationally, sexuality education is very context-specific and varies between types of schools and school cultures. Although the recently updated sexuality education guidelines in New Zealand include information about IP be included in classes, clarity is required regarding programme aims (e.g., discourage IP viewing, or encourage critical thinking), as well as critical reflection on how youth are constructed (i.e., agentic or naïve).

Furthermore, students may have varied needs that, among other things, vary by gender, and are currently not addressed by sexuality education curricula. Girls were less likely to have received any kind of education about IP than boys and gender diverse youth, consistent with a recent survey (Family Planning New Zealand, 2019). Girls may be receiving less education about IP due to the presumption that they either do not view IP or are not generally attracted to IP (Sorbring et al., 2015; Spišák, 2017). Curricula must also be relevant to gender diverse learners as despite improvements that focus on inclusivity, sexuality education curricula often mirrors the implicit heteronormativity of wider society (Chesir-Teran, 2003). This is suggested by the fact that gender diverse youth ranked school sixth as their source of information about sex and sexuality in general, in comparison to second by girls and boys. However, these young people also listed peers as their primary source of information, indicating a level of comfort in talking among friends about identity and sexuality (Jackson, 2004).

Thus, although young people ranked school second (after peers) as a primary educator about sex and sexuality-challenging the notion of IP as becoming their primary channel of sexuality education (Rothman et al., 2018; Tanton et al., 2015) these findings raise questions about whether the content is relevant and wholly valuable to them. In this regard, an important finding in the extant literature is the request from some youth to have IP discussed, not ignored, in a timely way during sexuality 
education in school and with caregivers as a way of helping them understand the content they may encounter online (Pound et al., 2016; Sørensen \& Knudsen, 2006). Some research suggests that, although youth take some basic information away from sexuality education, a key aspect that is lacking, based on their needs, is a discourse of erotics or desire (Allen, 2004). This observation coheres with our finding of the absence of teaching about IP. These findings point to a gap in the conversation that youth are having with caregivers and educators about sex, sexuality, and IP, as we will now elaborate on.

\section{Divergences Between Caregivers, Educators and Youth}

In line with previous findings, our results suggest that caregivers overestimate the likelihood of youth disclosure to them, while educators (who anticipate lack of disclosure) arguably have a more realistic understanding (Priebe et al., 2013; Wisniewski et al., 2017). Existing studies point to fear or embarrassment as potential reasons for youth non-disclosure, even when encounters with IP are unintentional (Rothman et al., 2017). Thus, whether young people feel comfortable or safe to disclose their encounters is a socio-cultural factor worth considering when examining some of our results, particularly the gendered patterns.

Aside from curiosity about sex and sexuality, there were differences between these caregivers, educators and youth regarding what motivates young people to view IP, indicating a disconnect in how youth and significant adults understand the function of IP in young people's lives, and their sexuality more broadly. Youth ranked IP as providing entertainment and relaxation in their top five motivations, which aligns with the literature (Attwood et al., 2018; Bale, 2011), while relaxation was ranked last across each of the adult stakeholder groups, so there are differing views about how youth perceive the role of IP in their lives, and how their caregivers and educators understand the meaning and presence of IP for youth.

Furthermore, that youth may be motivated to view IP on account of their friends was ranked in the top five across all adult groups, and ranked second after curiosity by caregivers (in comparison to 10th by youth themselves). Caregivers' attribution of youth IP viewing to peer pressure downplays the challenging notion of children as sexual beings and may to some extent preserve an image of childhood innocence (Jarkovská \& Lamb, 2018). The widespread and dominant Western view of children as innocent, pure and asexual (alongside sex as being improper and a source of taboo) has led to anxieties among caregivers about introducing sexual information too early or too much in their children's lives, which is reflected in the types of messages caregivers deliver to youth about IP (Lamb et al., 2018).

There was also a divergence in understanding between youth and their caregivers as to how prominently caregivers feature as sexuality educators in young people's lives in comparison to media (Sprecher et al., 2008). Boys and gender diverse participants selected IP as one of their top three sources of information about sex and sexuality (after peers and school, and peers and the Internet, respectively) (Allen, 2009; Scarcelli, 2014). As with previous research, this contrasts with girls' responses (Tanton et al., 2015). Unlike boys and gender diverse participants, girls 
did not include IP in their top three sources of information about sex and sexuality, ranking it only sixth. Thus, boys and gender diverse youth reported turning to IP for information about sex before going to caregivers, while girls reported going to the internet in general before caregivers.

In contrast, caregivers ranked themselves higher as a source of education than the Internet or IP. This was especially true for female caregivers who ranked themselves as youth's primary source of information about sex and sexuality. This could reflect a gendered expectation of mothers to place themselves in this role (Jackson, 2004; Sprecher et al., 2008). Men overestimated the role that IP plays as an information source compared to youth, ranking it second after peers, with gender diverse adults ranking it first.

These discrepancies suggests a disconnect between young people and adults that may need to be evaluated when considering how to best support youth in navigating IP and igniting relevant conversations about sexuality in general, and IP specifically (Jearey-Graham \& Macleod, 2015). How young people make sense of IP and how they construct their personal sexual identities in relation to their understandings of IP may differ to adults' constructions and perceptions of young people's experiences with IP (Healy-Cullen et al., 2021a). For example, caregiver communication with youth about IP not being 'real' assumes that youth are 'duped' by IP. In this way, adults position youth as unagentic and uncritical consumers of IP, despite research that suggests youth are engaging critically with this material (Goldstein, 2019; Spišák, 2017). Thus, further exploration is required of youth's sensemaking practices, signaling a move in direction from harms-focused effects research towards understanding what would be meaningful and beneficial for youth in terms of support.

\section{Understanding Gendered Patterns}

Variation in understanding between the stakeholder groups also appear to reflect gendered understandings of IP, as shown by gendered patterns that map across youth and adult findings. Wider social understandings are relevant to interpreting these findings. For example, boys and gender diverse youth reported that they watched IP for sexual gratification, and this was a primary motivation for viewing IP, which corresponds with existing research that consistently reports on young men's sexual excitement in relation to IP (Coy \& Horvath, 2018).

Girls listed curiosity rather than sexual gratification as their main reason for viewing IP and placed "as a way to learn about sex" third, which did not feature in the top five reasons given by boys or gender diverse youth. Such differences can be understood in relation to gendered meanings of pornography, which are underpinned by broader understandings of women's and men's sexual desire and what is considered appropriate gender behavior in sexual matters (Spišák, 2017). It is socially permissible for boys to show an interest in IP as a source of sexual pleasure, and so it was possibly easier for these participants to provide sexual gratification as their main reasons for viewing IP than their female counterparts (Tolman \& McClelland, 2011). Furthermore, as some research has shown, "girls 
perceive themselves as being unnatural if their desires do not revolve around boys" (Spišák, 2017, p. 368). Accordingly, the motivation of viewing IP to learn about sex and sexual acts given by girls — and not boys-may represent a socially desirable presentation of femininity. This use of IP as a learning tool for how to 'do' sex, for young girls especially, needs to be investigated further (Jackson \& Scott, 2007).

\section{Limitations}

There were several limitations of the present study. Difficulty in recruiting schools to participate on research related to sex and sexuality has been experienced by other researchers in New Zealand and internationally (e.g., Baker, 2016; Stanley et al., 2018), and this research was no exception. Uptake by schools was less than anticipated; nine of the 249 schools contacted agreed to participate. Although some principals commented that the research was important and timely, they declined to participate due to apprehension about the topic, drawing young people's attention to IP, time constraints, religious ethos of the school, and other characteristics of the school population. Thus, this is not a representative study; schools that participated were invested in some way in sexuality education more broadly. Our findings do not represent the views of youth and adults from schools where there is no such investment. Thus, using schools as research sites and principals as gatekeepers, while beneficial in some respects, was also potentially problematic in that power relations were exacerbated; only young people, educators, and caregivers associated with schools who agreed to participate had the opportunity to take part. Future work that seeks to make inferences based on group and/or gender should read these results within this context, and garner perspectives from a more representative sample.

A further limitation was the missing data for two questions related to the educators' group due to a problem with the survey setup that was not detected until data collection was completed. This meant that two questions (i.e., primary educators about sex and sexuality, and primary motivation for viewing IP) could not be explored in full.

We are aware that there are issues with measurements in this field of research (Fisher \& Kohut, 2020). Our questions were derived from the literature, and there are issues with that literature, just as there are issues with the use of Westernised, individual-orientated scientifically-grounded measurements/scales concerned with psychometric properties. Our research was exploratory, and our analyses were descriptive only. Hypotheses were not appropriate to the study aim, and we did not test for generalisable differences using inferential statistics given the nature of the sample. Future research that does aim to make inferences or make generalisations may wish to take a different analytical tack.

Finally, although not attended to in our research, there are documented differences in IP use not only by gender but also by sexual orientation (Bőthe et al., 2020). Future research could collect information about sexual orientation and consider how 
that may influence both youth experiences as well as access to sexuality education through domains of sexual socialisation such as caregivers and educators.

\section{Conclusion}

Overall, in keeping with international and local findings, these young New Zealanders are encountering IP, intentionally or otherwise, in the early teenage years. Although caregivers and educators are aware of youth encounters with IP, there is a lack of open communication between these significant adults and young people about the topic. Additionally, there are convergences and divergences in understanding youth encounters with IP between the stakeholder groups and across genders, particularly regarding youth motivations for viewing IP and youth's primary sources of information about sex and sexuality. More in-depth research with these three stakeholder groups, especially representing a broader range of perspectives about sexuality education, would be valuable in order to unpack these synergies and discrepancies, to ultimately inform how to best support youth in navigating IP. If IP is to be accepted as a new cultural resource for youth, the next step is to explore with youth how they make sense of such a resource, and how these understandings might manifest in gendered ways based on available social discourse. Thus, further research on the socio-cultural norms that exist to shape the gendered ways in which youth engage with IP would be valuable.

Acknowledgements This research is funded by a Massey University Doctoral Scholarship for full-time study towards a $\mathrm{PhD}$ degree at Massey University. We would like to express particular thanks to the schools and participants who took part in this research. We also thank Harvey Jones at Massey University for technical support.

Authors' Contribution All authors contributed to the study conception and design. Material preparation, data collection and analysis were performed by the first author. The first draft of the manuscript was written by the first author and all authors commented on previous versions of the manuscript. All authors contributed to interpretation of the data and approved the final manuscript.

Funding Open Access funding provided by the IReL Consortium. This research is funded by a Massey University Doctoral Scholarship for full-time study towards a PhD degree at Massey University.

Data Availability Please contact the lead author to request access to the data.

\section{Declarations}

Competing interests The authors declare no competing interests.

Ethics Approval This research was approved by the Massey University Human Ethics Committee: Southern B, Application SOB 18/51. Informed consent was obtained from all individual participants included in the study, and the procedures used in this study adhere to the tenets of the Declaration of Helsinki.

Open Access This article is licensed under a Creative Commons Attribution 4.0 International License, which permits use, sharing, adaptation, distribution and reproduction in any medium or format, as long as you give appropriate credit to the original author(s) and the source, provide a link to the Creative Commons licence, and indicate if changes were made. The images or other third party material in this article are included in the article's Creative Commons licence, unless indicated otherwise in a credit line to the 
material. If material is not included in the article's Creative Commons licence and your intended use is not permitted by statutory regulation or exceeds the permitted use, you will need to obtain permission directly from the copyright holder. To view a copy of this licence, visit http://creativecommons.org/licen ses/by/4.0/.

\section{References}

Albury, K. (2014). Porn and sex education, porn as sex education. Porn Studies, 1(1-2), 172-181. https:// doi.org/10.1080/23268743.2013.863654

Albury, K. (2018). Porn and participation: Implications for learning and teaching practice. Porn Studies. https://doi.org/10.1080/23268743.2017.1405739

Allen, L. (2004). Beyond the birds and the bees: Constituting a discourse of erotics in sexuality education. Gender and Education, 16(2), 151-167. https://doi.org/10.1080/09540250310001690555

Allen, L. (2009). 'It's not who they are it's what they are like': Re-conceptualising sexuality education's 'best educator'debate. Sex Education, 9(1), 33-49. https://doi.org/10.1080/14681810802639814

Ashton, S., McDonald, K., \& Kirkman, M. (2018). Women's experiences of pornography: A systematic review of research using qualitative methods. The Journal of Sex Research, 55(3), 334-347. https:// doi.org/10.1080/00224499.2017.1364337

Attwood, F. (2005). What do people do with porn? Qualitative research into the comsumption, use, and experience of pornography and other sexually explicit media. Sexuality and Culture, 9(2), 65-86. https://doi.org/10.1007/s12119-005-1008-7

Attwood, F., Smith, C., \& Barker, M. (2018). 'I'm just curious and still exploring myself': Young people and pornography. New Media \& Society, 20(10), 3738-3759. https://doi.org/10.1177/1461444818 759271

Baker, K. E. (2016). Online pornography-Should schools be teaching young people about the risks? An exploration of the views of young people and teaching professionals. Sex Education, 16(2), 213228. https://doi.org/10.1080/14681811.2015.1090968

Bale, C. (2011). Exploring young people's perceptions of the impact of sexualised media on their sexual health: A qualitative study. Doctoral dissertation, University of Sheffield. https://ethos.bl.uk/Order Details.do?uin=uk.bl.ethos. 574480

Boniel-Nissim, M., Efrati, Y., \& Dolev-Cohen, M. (2020). Parental mediation regarding children's pornography exposure: The role of parenting style, protection motivation and gender. The Journal of Sex Research, 57(1), 42-51. https://doi.org/10.1080/00224499.2019.1590795

Bőthe, B., Vaillancourt-Morel, M. P., Bergeron, S., \& Demetrovics, Z. (2019). Problematic and nonproblematic pornography use among LGBTQ adolescents: A systematic literature review. Current Addiction Reports, 6(4), 478-494. https://doi.org/10.1007/s40429-019-00289-5

Bőthe, B., Vaillancourt-Morel, M. P., Girouard, A., Štulhofer, A., Dion, J., \& Bergeron, S. (2020). A large-scale comparison of Canadian sexual/gender minority and heterosexual, cisgender adolescents' pornography use characteristics. The Journal of Sexual Medicine, 17(6), 1156-1167. https:// doi.org/10.1016/j.jsxm.2020.02.009

Bragg, S., \& Buckingham, D. (2009). Too much too young? Young people, sexual media and learning. In F. Attwood (Eds.), Mainstreaming sex: The sexualisation of Western culture (pp. 129-146). IB Tauris.

Braun, V., \& Clarke, V. (2012). Thematic analysis. In H. Cooper, P. M. Camic, D. L. Long, A. T. Panter, D. Rindskopf, \& K. J. Sher (Eds.), APA handbook of research methods in psychology: Research designs: Quantitative, qualitative, neuropsychological, and biological (Vol. 2, pp. 57-71). American Psychological Association.

Braun-Courville, D. K., \& Rojas, M. (2009). Exposure to sexually explicit web sites and adolescent sexual attitudes and behaviors. Journal of Adolescent Health, 45(2), 156-162. https://doi.org/10.1016/j. jadohealth.2008.12.004

Brown, J. D., \& L'Engle, K. L. (2009). X-rated: Sexual attitudes and behaviors associated with US early adolescents' exposure to sexually explicit media. Communication Research, 36(1), 129-151. https:// doi.org/10.1177/0093650208326465 
Chesir-Teran, D. (2003). Conceptualizing and assessing heterosexism in high schools: A setting-level approach. American Journal of Community Psychology, 31(3-4), 267-279. https://doi.org/10. 1023/A:1023910820994

Collier, K. L., Van Beusekom, G., Bos, H. M. W., \& Sandfort, T. G. M. (2013). Sexual orientation and gender identity/expression related peer victimization in adolescence: A systematic review of associated psychosocial and health outcomes. Journal of Sex Research, 50(3-4), 299-317. https://doi.org/ 10.1080/00224499.2012.750639

Coy, M., \& Horvath, M. A. H. (2018). Young people, pornography, and gendered sexual practices. In S. Lamb \& J. Gilbert (Eds.), The Cambridge handbook of sexual development: Childhood and adolescence (pp. 462-482). Cambridge University Press. https://doi.org/10.1017/9781108116121.024

Davis, A. C., Wright, C., Curtis, M., Hellard, M. E., Lim, M. S. C., \& Temple-Smith, M. J. (2019). 'Not my child': Parenting, pornography, and views on education. Journal of Family Studies. https://doi. org/10.1080/13229400.2019.1657929

Dawson, K. (2020). Establishing an evidence base for the development of porn literacy interventions for adolescents. Doctoral dissertation, National University of Ireland, Galway. ARAN - Access to Research at NUI Galway. http://hdl.handle.net/10379/15826.

Family Planning New Zealand. (2019). Young people's experiences of sexuality education. https://www. familyplanning.org.nz/media/303990/youth-survey-summary-report_march2019_final.pdf

Fisher, W. A., \& Kohut, T. (2020). Reading pornography: Methodological considerations in evaluating pornography research. The Journal of Sexual Medicine, 17(2), 195-209. https://doi.org/10.1016/j. jsxm.2019.11.257

Gesser-Edelsburg, A., \& Arabia, M. A. E. (2018). Discourse on exposure to pornography content online between Arab adolescents and parents: Qualitative study on its impact on sexual education and behavior. Journal of Medical Internet Research, 20(10), e11667. https://doi.org/10.2196/11667

Goldstein, A. (2019). Beyond porn literacy: Drawing on young people's pornography narratives to expand sex education pedagogies. Sex Education. https://doi.org/10.1080/14681811.2019.1621826

Healy-Cullen, S., Morison, T., Ross, K., \& Taylor, J. E. (2021a). Making sense of youth engagement with Internet pornography: Youths', parents', and educators' use of sexual scripts (Manuscript submitted for publication).

Healy-Cullen, S., Taylor, J. E., Morison, T., \& Ross, K. (2021b). Using Q-methodology to explore key stakeholder perspectives on porn literacy education. Sexuality Research and Social Policy. https:// doi.org/10.1007/s13178-021-00570-1

Jackson, S., \& Scott, S. (2007). Faking like a woman? Towards an interpretive theorization of sexual pleasure. Body \& Society, 13(2), 95-116. https://doi.org/10.1177/1357034X07077777

Jackson, S. (2004). Identifying future research needs for the promotion of young people's sexual health in New Zealand. Social Policy Journal of New Zealand, 21, 123-136.

Jarkovská, L., \& Lamb, S. (2018). Not innocent, but vulnerable: An approach to childhood innocence. In S. Lamb \& J. Gilbert (Eds.), The Cambridge handbook of sexual development: Childhood and adolescence (pp. 76-93). Cambridge University Press. https://doi.org/10.1017/9781108116121.005

Jearey-Graham, N., \& Macleod, C. (2015). A discourse of disconnect: Young people from the Eastern Cape talk about the failure of adult communications to provide habitable sexual subject positions. Perspectives in Education, 33(2), 11-29.

Lamb, S., White, L., \& Plocha, A. (2018). Are children sexual? Who, what, where, when, and how? In S. Lamb \& J. Gilbert (Eds.), The Cambridge handbook of sexual development: Childhood and adolescence (pp. 17-34). Cambridge University Press. https://doi.org/10.1017/9781108116121.002

Lim, M. S. C., Agius, P. A., Carrotte, E. R., Vella, A. M., \& Hellard, M. E. (2017). Young Australians' use of pornography and associations with sexual risk behaviours. Australian and New Zealand Journal of Public Health, 41(4), 438-443. https://doi.org/10.1111/1753-6405.12678438

Livingstone, S., \& Bober, M. (2004). UK children go online: Surveying the experiences of young people and their parents. London School of Economics and Political Science. http://www.children-goonline.net/

Löfgren-Mårtenson, L., \& Månsson, S.-A. (2010). Lust, love, and life: A qualitative study of Swedish adolescents' perceptions and experiences with pornography. Journal of Sex Research, 47(6), 568579. https://doi.org/10.1080/00224490903151374

Martellozzo, E., Monaghan, A., Adler, J. R., Davidson, J., Leyva, R., \& Horvath, M. A. H. (2017). “... I wasn't sure it was normal to watch it...". A quantitative and qualitative examination of the impact of online pornography on the values, attitudes, beliefs and behaviours of children and young people. Middlesex University London. https://doi.org/10.6084/m9.figshare.3382393 
Mattebo, M., Larsson, M., Tydén, T., \& Häggström-Nordin, E. (2014). Professionals' perceptions of the effect of pornography on Swedish adolescents. Public Health Nursing, 31(3), 196-205. https://doi. org/10.1111/phn.12058

Office of Film and Literature Classification. (2018). NZ Youth and Porn: Research findings of a survey on how and why young New Zealanders view online pornography. https://www.classificationoffice. govt.nz/assets/PDFs/NZYouthPornOFLC-December2018-PrintVersion.pdf

Ollis, D. (2016). The challenges, contradictions and possibilities of teaching about pornography in sex and relationships education (SRE): The Australian context. In V. Sundaram \& H. Sauntson (Eds.), Global perspectives and key debates in sex and relationships education: Addressing issues of gender, sexuality, plurality and power (pp. 48-67). Springer.

Peter, J., \& Valkenburg, P. M. (2016). Adolescents and pornography: A review of 20 years of research. The Journal of Sex Research, 53(4-5), 509-531. https://doi.org/10.1080/00224499.2016.1143441

Pound, P., Langford, R., \& Campbell, R. (2016). What do young people think about their school-based sex and relationship education? A qualitative synthesis of young peoples views and experiences. British Medical Journal Open, 6(9), e011329. https://doi.org/10.1136/bmjopen-2016-011329

Priebe, G., Mitchell, K., \& Finkelhor, D. F. (2013). To tell or not to tell? Youth's responses to unwanted internet experiences. Cyberpsychology. https://doi.org/10.5817/CP2013-16

Rothman, E. F., Adhia, A., Christensen, T. T., Paruk, J., Alder, J., \& Daley, N. (2018). A pornography literacy class for youth: Results of a feasibility and efficacy pilot study. American Journal of Sexuality Education, 13(1), 1-17. https://doi.org/10.1080/15546128.2018.1437100

Rothman, E. F., Paruk, J., Espensen, A., Temple, J. R., \& Adams, K. (2017). A qualitative study of what US parents say and do when their young children see pornography. Academic Pediatrics, 17(8), 844-849. https://doi.org/10.1016/j.acap.2017.04.014

Scarcelli, C. M. (2014). "One way or another I need to learn this stuff!" Adolescents, sexual information, and the Internet's role between family, school, and peer groups. Interdisciplinary Journal of Family Studies, 19(1), 40-59.

Ševčíková, A., \& Daneback, K. (2014). Online pornography use in adolescence: Age and gender differences. European Journal of Developmental Psychology, 11(6), 674-686. https://doi.org/10.1080/ 17405629.2014.926808

Short, M. B., Black, L., Smith, A. H., Wetterneck, C. T., \& Wells, D. E. (2012). A review of Internet pornography use research: Methodology and content from the past 10 years. Cyberpsychology, Behavior, and Social Networking, 15(1), 13-23. https://doi.org/10.1089/cyber.2010.0477

Shtarkshall, R. A., Santelli, J. S., \& Hirsch, J. S. (2007). Sex education and sexual socialisation: Roles for educators and parents. Perspectives on Sexual and Reproductive Health, 39(2), 116-119. https://doi. org/10.1363/3911607

Sorbring, E., Hallberg, J., Bohlin, M., \& Skoog, T. (2015). Parental attitudes and young people's online sexual activities. Sex Education, 15(2), 129-143. https://doi.org/10.1080/14681811.2014.981332

Sørensen, D. A., \& Knudsen, V. S. (2006). Young people, gender and pornography in the Nordic countries: Final report. Nordic Council of Ministers.

Spišák, S. (2017). Negotiating norms: Girls, pornography and sexual scripts in finnish question and answer forum. Young, 25(4), 359-374. https://doi.org/10.1177/1103308816660482

Sprecher, S., Harris, G., \& Meyers, A. (2008). Perceptions of sources of sex education and targets of sex communication: Sociodemographic and cohort effects. The Journal of Sex Research, 45(1), 17-26. https://doi.org/10.1080/00224490701629522

Stanley, N., Barter, C., Wood, M., Aghtaie, N., Larkins, C., Lanau, A., \& Överlien, C. (2018). Pornography, sexual coercion and abuse and sexting in young people's intimate relationships: A European study. Journal of Interpersonal Violence, 33(19), 2919-2944. https://doi.org/10.1177/0886260516 633204

Štulhofer, A., Buško, V., \& Landripet, I. (2010). Pornography, sexual socialisation, and satisfaction among young men. Archives of Sexual Behavior, 39(1), 168-178. https://doi.org/10.1007/ s10508-008-9387-0

Tanton, C., Jones, K. G., Macdowall, W., Clifton, S., Mitchell, K. R., Datta, J., Lewis, R., Field, N., Sonnenberg, P., Stevens, A., Wellings, K., Johnson, A. M., \& C. H., M. . (2015). Patterns and trends in sources of information about sex among young people in Britain: evidence from three National Surveys of Sexual Attitudes and Lifestyles. British Medical Journal Open. https://doi.org/10.1136/ bmjopen-2015-007834 
Taylor, K. (2020). 'Accessing something that's meant to be inaccessible': Pornography viewers' reconciliation between early pornographic memories and pornography's perceived risk. Porn Studies. https:// doi.org/10.1080/23268743.2020.1736609

Tolman, D. L. (2013). It's bad for us too: How the sexualization of girls impacts the sexuality of boys, men, and women. In E. L. Zurbriggen \& T. Roberts (Eds.), The sexualization of girls and girlhood: Causes, consequences, and resistance (pp. 84-106). Oxford University Press.

Tolman, D. L., \& McClelland, S. I. (2011). Normative sexuality development in adolescence: A decade in review, 2000-2009. Journal of Research on Adolescence, 21(1), 242-255. https://doi.org/10.1111/j. 1532-7795.2010.00726.x

Tomić, I., Burić, J., \& Štulhofer, A. (2017). Associations between croatian adolescents' use of sexually explicit material and sexual behavior: Does parental monitoring play a role? Archives of Sexual Behavior. https://doi.org/10.1007/s10508-017-1097-z

Tsaliki, L. (2011). Playing with porn: Greek children's explorations in pornography. Sex Education, 11(3), 293-302. https://doi.org/10.1080/14681811.2011.590087

Weaver, A. D., Byers, E. S., Sears, H. A., Cohen, J. N., \& Randall, H. E. S. (2001). Sexual health education at school and at home: Attitudes and experiences of New Brunswick parents. Canadian Journal of Human Sexuality, 11(1), 19-32.

Widman, L., Javidi, H., Maheux, A. J., Evans, R., Nesi, J., \& Choukas-Bradley, S. (2021). Sexual communication in the digital age: Adolescent sexual communication with parents and friends about sexting, pornography, and starting relationships. Sexuality \& Culture. https://doi.org/10.1007/ s12119-021-09866-1

Wisniewski, P., Xu, H., Rosson, M. B., \& Carroll, J. M. (2017). Parents just don't understand: Why teens don't talk to parents about their online risk experiences. In Proceedings of the 2017 ACM conference on computer supported cooperative work and social computing (pp. 523-540). Association for Computing Machinery. https://doi.org/10.1145/2998181.2998236

Ybarra, M. L., \& Mitchell, K. J. (2005). Exposure to Internet pornography among children and adolescents: A national survey. CyberPsychology \& Behavior, 8(5), 473-486. https://doi.org/10.1089/cpb. 2005.8.473

Zurcher, J. D. (2017). Exploring descriptive norms of parent-child communication about pornography among parents of middle-schoolers in the US. Journal of Children and Media, 11(4), 381-398. https://doi.org/10.1080/17482798.2017.1312471

Publisher's Note Springer Nature remains neutral with regard to jurisdictional claims in published maps and institutional affiliations. 